\title{
Antifungal Activity of a Synthetic Cationic Peptide against the Plant Pathogens Colletotrichum graminicola and Three Fusarium Species
}

\author{
Eric T. Johnson ${ }^{1 *}$, Kervin O. Evans ${ }^{2}$ and Patrick F. Dowd ${ }^{1}$ \\ ${ }^{1}$ Crop Bioprotection Research Unit, USDA Agricultural Research Service, Peoria, IL 61604-3902, USA \\ ${ }^{2}$ Renewable Product Technology Research Unit, USDA Agricultural Research Service, Peoria, IL 61604-3902, USA
}

(Received on April 15, 2015; Accepted on May 30, 2015)

A small cationic peptide (JH8944) was tested for activity against a number of pathogens of agricultural crops. JH8944 inhibited conidium growth in most of the tested plant pathogens with a dose of $50 \mu \mathrm{g} / \mathrm{ml}$, although one isolate of Fusarium oxysporum was inhibited at $5 \mu \mathrm{g} /$ ml of JH8944. Most conidia of Fusarium graminearum were killed within 6 hours of treatment with $50 \mu \mathrm{g}$ / $\mathrm{ml}$ of JH8944. Germinating $F$. graminearum conidia required $238 \mu \mathrm{g} / \mathrm{ml}$ of $\mathbf{J H 8 9 4 4}$ for $\mathbf{9 0 \%}$ growth inhibition. The peptide did not cause any damage to tissues surrounding maize leaf punctures when tested at a higher concentration of $250 \mu \mathrm{g} / \mathrm{ml}$ even after 3 days. Liposomes consisting of phosphatidylglycerol were susceptible to leakage after treatment with 25 and $50 \mu \mathrm{g} /$ $\mathrm{ml}$ of JH8944. These experiments suggest this peptide destroys fungal membrane integrity and could be utilized for control of crop fungal pathogens.

Keywords : antifungal peptide, membrane-active mechanism, non-phytotoxic

Many Fusarium and Colletotrichum fungi cause diseases in crops. Infected plant tissues can contain mycotoxins produced by Fusarium fungi, which are harmful to humans and livestock. The Food and Agriculture Organization has predicted that approximately $25 \%$ of the world's crops become contaminated with mycotoxins each year that results in a loss of 1 billion metric tons of food and food products (Schmale and Munkvold, 2014). Discovery of novel antifungal compounds can potentially mitigate severe crop losses caused by these fungi. Antimicrobial peptides (AMPs) often permeate and disrupt the fungal cell membrane (Lee and Lee, 2009; Regente et al., 2005) and are

*Corresponding author.

Phone) +1-309-681-6177, FAX) +1-309-681-6686

E-mail) eric.johnson2@ars.usda.gov promising as commercial antifungal compounds because of declining production costs (Duncan and O'Neill, 2013) and the reduced likelihood of developing resistance compared to traditional antibiotics (Zasloff, 2002). Furthermore AMPs can be transgenically expressed in plants for control of fungal pathogens (Abdallah et al., 2010; Ghag et al., 2012; Koch et al., 2012).

Three short, synthetic cationic peptides with similarity to histatin and lactoferricin had fungicidal properties against clinical isolates of Candida albicans but did not kill human erythrocytes at the fungal minimum inhibitory concentration (Nikawa et al., 2004). Further studies determined that one of the peptides, JH8194, unexpectedly induced osteoblast differentiation (Makihira et al., 2011). JH8195, another cationic peptide sharing $71 \%$ sequence identity with JH8194, could possibly also induce osteoblast differentiation. The third peptide, JH8944, had only $8 \%$ sequence identity to JH8194, and might not cause unintended effects on human cells. In this study, we investigated the activity of JH8944 against a number of important leaf and grain infecting plant endophytes and pathogens, including ones that produce mycotoxins.

Fusarium verticillioides strains F2 and F4 were isolated from symptomless corn kernels grown in central Illinois by R. Proctor. The strains were isolated with peptone PCNB (pentachloronitrobenzene) agar medium amended with streptomycin and neomycin as described by Leslie and Sommerell (2006). Fusarium graminearum Strain III-B was isolated in pure culture from a diseased wheat head exhibiting symptoms of Fusarium head blight in a field plot at the USDA-ARS research facility in Peoria, Illinois by D. Schisler. The isolate was used to inoculate healthy wheat and identical symptoms of Fusarium head blight developed. The identity of the isolate was confirmed using traditional taxonomic as well as molecular techniques.

To obtain spores for assays, $F$. graminearum was grown on clarified V8 media (V8 juice was centrifuged 5-10 $\min$ at 3,220 g, and the supernatant used at $17.6 \%, \mathrm{v} / \mathrm{v}$, 
and included $5.2 \mathrm{~g} / 1$ calcium carbonate) with 12 hour of fluorescent lighting per day at room temperature. The $F$. verticillioides strains were grown on V8 media (20\% V8 juice, $3 \mathrm{~g} / \mathrm{l}$ calcium carbonate) at room temperature in the dark. Colletotrichum graminicola (NRRL 13649, isolated from maize, and 13650, isolated from Medicago sp.) and F. oxysporum (NRRL 28184, isolated from a corn cob, and 38346, isolated from bean) were obtained from the ARS Culture Collection (Peoria, IL) and grown on potato dextrose agar. $F$. oxysporum produced conidia in the dark whereas $C$. graminicola produced conidia after 12 hours (NRRL 13650) or 24 hours (NRRL 13649) of fluorescent lighting. Hyphal fragments and conidium-bearing structures were suspended in sterile water and conidia were isolated by filtering through sterile Miracloth.

Conidia were diluted into potato dextrose broth (PDB) at $3.6 \times 10^{4}$ conidia/ml. JH8944 (FKCKKVVISLRRY) was synthesized to $98 \%$ purity (Peptide 2.0, Chantilly, VA, USA) and dissolved in water. Nystatin (Sigma-Aldrich, St. Louis, MO, USA), dissolved in methanol, served as a positive antifungal control. The compounds were evaluated in 96 well plates (BD Falcon Microtest Primaria, Becton Dickinson, Franklin Lakes, NJ, USA) at concentrations of $0.25,1,2,3,5,10,25$, and $50 \mu \mathrm{g} / \mathrm{ml}$ (final volume of 200 $\mu 1$ ) as previously described (Wicklow and Poling, 2009) with some modifications. Four replicates were tested at each concentration, as well as four solvent control replicates. The plates were incubated at room temperature in the dark and the amount of growth was determined by the absorbance of each well at $550 \mathrm{~nm}$ with a SpectraMax 250 plate reader (Molecular Devices, Sunnyvale, CA, USA). Readings were taken daily until at least one solvent control value reached or exceeded $\sim 0.5$ absorbance units, which took 3-5 days. Single outlier absorbance values were removed when the $\mathrm{Q}$ test exceeded the $90 \%$ confidence value $(0.765)$. The $\mathrm{GI}_{90}$ was assigned to the treatment concentration that resulted in $90 \%$ or greater growth inhibition compared to the control, as indicated by differences in absorbance.

F. graminearum conidia were diluted into $\mathrm{PDB}$ at $3.8 \times$ $10^{4}$ conidia $/ \mathrm{ml}$. The conidia were kept at room temperature and then examined using a light microscope for levels of germination after $7 \mathrm{~h}$. At least $93 \%$ of the examined conidia (163-177 conidia scored) had germinated by this time. JH8944 was added to the germinated conidia in PDB at concentrations of 125 and $238 \mu \mathrm{g} / \mathrm{ml}$ (four replicates for each concentration) and conidia growth was compared to control (sterile water added) germinated conidia over three days in 96 well plates as described above. Statistical comparisons between treated and control samples were determined using analysis of variance with SAS software version 9.2 using procedure GLM.

Ohio 43 maize seed (obtained from USDA-ARS North Central Regional Plant Introduction Station) was sown and grown in pots using soil and fertilizer composition number 3 in a plant growth room as previously described (Dowd et al., 2007). Leaf segments (approximately $1 \times 2 \mathrm{~cm}$ ) were excised from the second leaf of a three leaf plant. The tip of a jeweler's screwdriver was sharpened and used to make four equally spaced $0.8 \mathrm{~mm}$ slits in leaf segments. Two

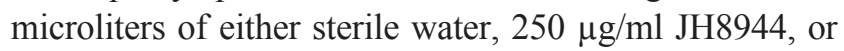
$2.5 \mathrm{mg} / \mathrm{ml}$ oxalic acid (positive control) was added to each slit, and the leaves were placed in small Petri dishes with tight fitting lids containing moistened filter paper (Dowd et al., 2012). Leaf segments (3-5 leaves per treatment) were evaluated for the width of the necrotic tissue from the edge of the slit under a $20 \times$ stereoscope each day for 3 days.

$F$. graminearum conidia were diluted to $3.8 \times 10^{4}$ conidia/ml in PDB and the number of colony forming units (cfu) were calculated by diluting 1:50 in water and spreading $100 \mu \mathrm{l}$ on V8 plates (triplicate measurements). Microcentrifuge tubes containing conidia in PDB and JH8944 at $50 \mu \mathrm{g} / \mathrm{ml}$ or sterile water were prepared in triplicate and incubated at room temperature in the dark. Dilution plates were made (in triplicate) from the tubes after 2, 4 and $6 \mathrm{~h}$ of incubation, and kept at room temperature with $12 \mathrm{~h}$ of fluorescent lighting daily. The number of cfus on the dilution plates were counted within the next 48 hours. Significant statistical differences between the $0 \mathrm{~h}$ mean number of cfus and the mean number of cfus of the later samplings were determined using analysis of variance with SAS software version 9.2 using procedure GLM. F. graminearum conidia from the above PDB dilution were also treated with $50 \mu \mathrm{g} /$ $\mathrm{ml} \mathrm{JH8944} \mathrm{or} \mathrm{sterile} \mathrm{water} \mathrm{and} \mathrm{added} \mathrm{in} \mathrm{quadruplicate} \mathrm{to} \mathrm{a}$ 96 well plate and monitored for growth as described above.

Liposome leakage experiments were completed to determine the mechanism of action of JH8944. The following chemicals were utilized: sodium chloride (Fisher), 2-[(2-Hydroxy-1,1-bis(hydroxymethyl)ethyl)amino] ethanesulfonic acid (TES, Sigma Aldrich), 8-Aminonaphthalene-1,3,6-Trisulfonic Acid (ANTS, Life Technologies), p-Xylene-Bis-Pyridinium Bromide (DPX, Life Technologies), 1,2-dioleoyl-sn-glycero-3-phospho-(1'-rac-glycerol) (DOPG; Avanti Polar Lipids, Inc, Alabaster, AL), and 1,2-dioleoyl-sn-glycero-3-phosphocholine (DOPC; Avanti Polar Lipids, Inc.). Liposomes were prepared as previously described (Evans, 2006), using the extrusion method (Olson et al., 1979) Briefly, an appropriate amount of DOPC or DOPG lipids in chloroform was added to an amber vial, dried to a thin film under a gentle stream of argon and fur- 
ther dried overnight under vacuum. The liposome leakage assay, following the procedure of Parente and Lentz (1986), consisted of mixing equal volumes of $25 \mathrm{mM}$ ANTS, 40 $\mathrm{mM} \mathrm{NaCl}, 10 \mathrm{mM}$ TES, $\mathrm{pH} 7.4$ and $90 \mathrm{mM}$ DPX, $40 \mathrm{mM}$ $\mathrm{NaCl}, 10 \mathrm{mM}$ TES, pH 7.4 in a vial to give a leakage buffer containing $12.5 \mathrm{mM}$ ANTS, $45 \mathrm{mM}$ DPX, $40 \mathrm{mM}$ $\mathrm{NaCl}, 10 \mathrm{mM}$ TES, $\mathrm{pH}$ 7.4. The leakage buffer was used to hydrate dried DOPC or DOPG lipids. Lipids were vigorously mixed periodically for $30 \mathrm{~min}$, put through five freeze/thaw cycles (ethanol on dry ice $/ 60^{\circ} \mathrm{C}$ water bath), and extruded through two double-stacked 100$\mathrm{nm}$ pore filters in a LiposoFast extruder (Avestin, Inc; Ontario, Canada). The leakage buffer that was not encapsulated by liposomes was removed by passing the liposomes down a Sephadex G-75 column equilibrated with 2 mM TES, 100 mM NaCl, pH 7.4 (column buffer). Fluorescence measurements were conducted using a Fluorolog 3.21 (Horiba; Edison, NJ) with an excitation of $350 \mathrm{~nm}$ and an emission of $525 \mathrm{~nm}$. Liposomes containing the leakage buffer were incubated with various concentrations of peptide for 15 min prior to measuring fluorescence signal. Background measurements were conducted using liposomes hydrated with the column buffer. All measurements were conducted in triplicate.

Synthetic JH8944 peptide was tested against five Fusarium isolates as well as two isolates of C. graminicola (Table 1). F. oxysporum NRRL 28184 was the most sensitive to JH8944, as $>90 \%$ of conidia failed to grow with $5 \mu \mathrm{g} / \mathrm{ml}$ while the other $F$. oxysporum isolate, $C$. graminicola, $F$. graminearum and $F$. verticillioides $\mathrm{F} 2$ isolates required 50 $\mu \mathrm{g} / \mathrm{ml}$ to inhibit greater than $90 \%$ of growth from conidia compared to the control. Fifty $\mu \mathrm{g} / \mathrm{ml}$ of JH8944 inhibited approximately $50 \%$ of growth from conidia of $F$. verticillioides F4 isolate compared to the controls. All of the tested fungi were more sensitive to nystatin, a polyene macrolide produced in Streptomyces noursei (Brown et

Table 1. Antifungal activity of JH8944 in Fusarium and Colletotrichum fungi

\begin{tabular}{lcc}
\hline Fungus & JH8944 $\mathrm{GI}_{90}$ & Nystatin $\mathrm{GI}_{90}$ \\
\hline C. graminicola NRRL 13649 & 50 & 1 \\
C. graminicola NRRL 13650 & 50 & 2 \\
F. graminearum III-B & 50 & 1 \\
F. oxysporum NRRL 28184 & 5 & 3 \\
F. oxysporum NRRL 38346 & 50 & 5 \\
F. verticillioides F2 & 50 & 5 \\
F. verticillioides F4 & $>50$ & 3 \\
\hline
\end{tabular}

Concentrations tested were $0.25,1,2,3,5,10,25$, and $50 \mu \mathrm{g} / \mathrm{ml}$. GI ${ }_{90}$ $=$ growth inhibition $>90 \%$ relative to the control al., 1953). However, JH8944 was almost as effective as nystatin against $F$. oxysporum NRRL 28184. An additional experiment allowed $F$. graminearum conidia to germinate in PDB at room temperature for at least $7 \mathrm{~h}$ before the addition of JH8944. Further growth of the germinated conidia was inhibited $30 \%$ compared to the control with $125 \mu \mathrm{g} / \mathrm{ml}$ JH8944 $(P<0.0001)$ while further growth was completely inhibited by $238 \mu \mathrm{g} / \mathrm{ml} \mathrm{JH} 8944$.

Time-course viability experiments were completed to determine if JH8944 is fungicidal against conidia and if this effect requires prolonged exposure. Fifty $\mu \mathrm{g} / \mathrm{ml} \mathrm{JH} 8944$ dramatically reduced the number of viable $F$. graminearum conidia after 2, 4, and 6 hours of treatment as measured by dilution plating of treated conidia $(29 \pm 0.6$ cfus at time 0 ; $3 \pm 1$ cfus after $2 \mathrm{~h} ; 3 \pm 2$ cfus after $4 \mathrm{~h} ; 1 \pm 1$ cfus after 6 $\mathrm{h}$; mean \pm standard error at $2 \mathrm{~h}, 4 \mathrm{~h}$ and $6 \mathrm{~h}$ statistically significant at $P<0.05$ versus time 0 mean). A number of viable $F$. graminearum conidia failed to grow under control conditions after 6 hours for unknown reasons (10 $\pm 2 \mathrm{cfu})$. This indicated that approximately $90 \%$ of the conidia were killed by JH8944 after $6 \mathrm{~h}$. Control conidia growing in a 96 well plate under the same conditions as that of the $0-6 \mathrm{~h}$ conidia treatments had a mean absorbance of 0.387 at 595 $\mathrm{nm}(\mathrm{N}=4)$ after $46 \mathrm{~h}$ while conidia treated with $50 \mu \mathrm{g} / \mathrm{ml}$ JH8944 had a mean absorbance of 0.009 at $595 \mathrm{~nm}(\mathrm{~N}=4)$. This indicates that while some control conidia were unable to grow during the incubation process, this did not impede the remaining conidia from growing. Conidia did not grow

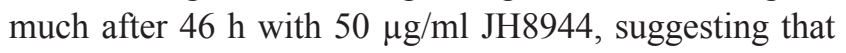
most $F$. graminearum conidia were killed by 6 hours.

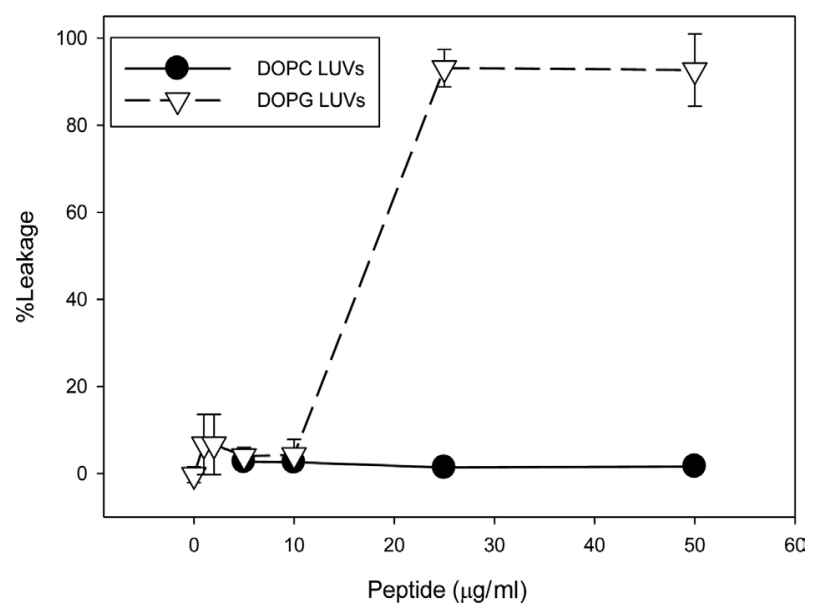

Fig. 1. Model membrane vesicles rupture with exposure to JH8944. LUVs composed of phosphatidylcholine (DOPC, circles) and phosphatidylglycerol (DOPG, triangles) were treated with increasing concentrations of JH8944. LUV leakage was measured $15 \mathrm{~min}$ after addition of peptide. 
The ability of JH8944 to induce leakage in model membranes (LUVs) was tested. No leakage was detected with LUVs made with the zwitterionic phospholipid phosphatidylcholine, while LUVs made with the anionic phospholipid phosphatidylglycerol displayed significant leakage ( $90 \%$ ) with 25 and $50 \mu \mathrm{g} / \mathrm{ml} \mathrm{JH8944} \mathrm{(Fig.} \mathrm{1).} \mathrm{These} \mathrm{data}$ suggest that the cationic peptide JH8944 is most effective against anionic phospholipids.

Plant protection from pathogens using JH8944 could be achieved through transgenic expression or by aerial application. However, it is not known if JH8944 is toxic to plant cells. To test for phytotoxicity, $2 \mu \mathrm{l}$ droplets of $250 \mu \mathrm{g} /$ $\mathrm{ml} \mathrm{JH8944} \mathrm{were} \mathrm{added} \mathrm{to} \mathrm{punctures} \mathrm{in} \mathrm{maize} \mathrm{leaves.} \mathrm{No}$ necrotic zones were observed in JH8944 treated $(\mathrm{N}=12)$ or water control $(\mathrm{N}=12)$ punctures after three days of observation. Conversely, $1.2 \mathrm{~mm}$ wide necrotic zones $(\mathrm{SE}=0.16$, $\mathrm{N}=20$ ) were observed in punctures treated with oxalic acid, an inducer of programmed cell death (Errakhi et al., 2008).

The primary aim of the current study was to determine the efficacy of using JH8944 as an antimicrobial peptide against fungal pathogens of maize and sorghum. The effective concentration of JH8944 (50 $\mu \mathrm{g} / \mathrm{ml})$ against Fusarium and Colletotrichum conidia in our study are close to the concentrations of JH8944 (16 and $41 \mu \mathrm{g} / \mathrm{ml}$ ) effective against two isolates of $C$. albicans (Nikawa et al., 2004). Higher concentrations of JH8944 are likely needed to reduce growth of conidia that have germinated. While there are antifungal compounds (e.g. nystatin) with lower effective concentrations, the appeal for using JH8944 as an antifungal compound centers on its small size of 10 amino acids. Duncan and O'Neil (2013) argue that peptide antibiotics are a viable commercial possibility as large amounts of high quality peptides can be made. Advances in encapsulation could also enable peptides to be delivered in agricultural fields (Kumar et al., 2014).

Most conidia $(\sim 90 \%)$ of $F$. graminearum were killed within $6 \mathrm{~h}$ of exposure to $50 \mu \mathrm{g} / \mathrm{ml}$ of JH8944. Melittin, a 26 amino acid pore-forming antimicrobial peptide from the venom of the honey bee (Matsuzaki et al., 1997), killed most ( 95\%) C. albicans cells after $6 \mathrm{~h}$ of exposure (Lee and Lee, 2009). Rev-NIS, a 10 amino acid synthetic peptide based on the nuclear entry inhibitory signal peptide of HIV-1 Rev protein, killed approximately $70 \%$ of the $C$. albicans cells after $6 \mathrm{~h}$ of exposure (Lee and Lee, 2009). Rev-NIS is postulated to disrupt fungal plasma membranes (Lee and Lee, 2009). The similarity in fungal cell killing dynamics between JH8944, melittin and Rev-NIS suggests that JH8944 may also disrupt fungal plasma membranes.
JH8944 caused leakage of model membranes containing anionic phospholipids. Similarly, a $10 \mathrm{kDa}$ plant lipid transfer protein, Ha-AP10, caused leakage of phosphatidylglycerol LUVs but not phosphatidylcholine LUVs (Regente et al., 2005). Ha-AP10 killed nearly all Fusarium solani conidia at $50 \mu \mathrm{g} / \mathrm{ml}$, probably by disrupting the fungal membrane (Regente et al., 2005). Our results and the Regente et al. (2005) study further suggests that the failure of fungal conidia to grow caused by short (JH8944) or larger (Ha-AP10) peptides occurs by membrane disruption.

Droplets of JH8944 (at $250 \mu \mathrm{g} / \mathrm{ml}$ ) did not cause phytotoxicity at puncture sites in maize leaves, suggesting that JH8944 could be transgenically expressed in maize for fungal pathogen control. There are at least two examples in the scientific literature of antimicrobial peptides with in vitro antifungal activity similar to JH8944 that were also utilized as transgenic resistance molecules in plants. A 24 amino acid peptide, Myp30, a magainin analog, completely inhibited germination of Peronospora tabacina conidia at $50 \mu \mathrm{g} /$ $\mathrm{ml}$ (Li et al., 2001). Constitutive expression of the Myp30 peptide in the extracellular space of tobacco reduced the number of $P$. tabacina spores, and shortened fungal lesion diameters in infected transgenic leaves compared to the infected control leaves ( $\mathrm{Li}$ et al., 2001). MsrA1, a 34 amino acid peptide combining residues of cecropin at the $\mathrm{N}$-terminus and melittin at the C-terminus (Osusky et al., 2000 ), inhibited $75 \%$ of in vitro mycelial growth of $M y$ cosphaerella fijiensis strain 205019 at $51 \mu \mathrm{g} / \mathrm{ml}$ (Vásquez et al., 2009). Transgenic constitutive expression of MsrA1 peptide in Desiree potato plants conferred enhanced resistance to infection by Phytophthora cactorum and Fusarium soloni (Osusky et al., 2000). These findings indicate that the in vitro antifungal activity of JH8944 as measured in the current study could be developed into effective fungal resistance in transgenic plants in the future.

On the other hand, JH8944 might be useful in spray formulations for application to prevent plant disease problems. Large amounts of bioactive peptides were produced by Escherichia coli or Pichia pastoris (Long et al., 2012; Wang et al., 2014). Antifungal peptides sprayed on tomato leaves $22 \mathrm{~h}$ after fungal conidia inoculation significantly reduced the amount of fungal material in the leaves $48 \mathrm{~h}$ after peptide application (Zeitler et al., 2013).

We believe JH8944 should be further developed for control of maize pathogens, as it was effective against a number of maize pathogens at concentrations that did not show any phytotoxicity. JH8944 also has the potential to control pathogens of other crops as in the present study it was 10fold more effective against a bean-derived isolate of $F$. 
oxysporum than an F.oxysporum isolate from maize.

\section{Acknowledgments}

We are grateful to Chris Skory, Daren Brown, and Robert Proctor for comments on a draft manuscript. We thank Mark Doehring for technical assistance. We appreciate Robert Proctor and David Schisler for providing the $F$. verticillioides and $F$. graminearum strains, respectively. We also thank the ARS Culture Collection (NRRL) for providing the $F$. oxysporum and $C$. graminicola isolates and the North Central Regional Plant Introduction Station for supplying the Ohio 43 seed. This study was supported by funds from ARS projects 5010-42000-047-00 and 5010-41000-153-00. The mention of firm names or trade products in this manuscript does not imply that they are endorsed or recommended by the USDA over other firms or similar products not mentioned. USDA is an equal opportunity provider and employer.

\section{References}

Abdallah, N. A., Shah, D., Abbas, D. and Madkour, M. 2010. Stable integration and expression of a plant defensin in tomato confers resistance to Fusarium wilt. GM Crops 1:344-350.

Brown, R., Hazen, E. L. and Mason, A. 1953. Effect of fungicidin (nystatin) in mice injected with lethal mixtures of aureomycin and Candida albicans. Science 117:609-610.

Dowd, P. F., Johnson, E. T. and Pinkerton, T. S. 2007. Oral toxicity of $\beta-N$-acetyl hexosaminidase to insects. J. Agric. Food Chem. 55:3421-3428.

Dowd, P. F., Johnson, E. T. and Price, N. P. 2012. Enhanced pest resistance of maize leaves expressing monocot crop plant-derived ribosome-inactivating proteins and agglutinin. J. Agric. Food Chem. 60:10768-10775.

Duncan, V. M. S. and O'Neil, D. A. 2013. Commercialization of antifungal peptides. Fungal Biol. Rev. 26:156-165.

Errakhi, R., Meimoun, P., Lehner, A., Vidal, G., Briand, J., Corbineau, F., Rona, J. P. and Bouteau, F. 2008. Anion channel activity is necessary to induce ethylene synthesis and programmed cell death in response to oxalic acid. J. Exp. Bot. 59:3121-3129.

Evans, K. O. 2006. Room-temperature ionic liquid cations act as short-chain surfactants and disintegrate a phospholipid bilayer. Colloids and Surfaces A: Physiochem. Engineer. Aspects 274:11-17.

Ghag, S. B., Shekhawat, U. K. and Ganapathi, T. R. 2012. Petunia floral defensins with unique prodomains as novel candidates for development of Fusarium wilt resistance in transgenic banana plants. PLoS ONE 7:e39557.

Koch, A., Khalifa, W., Landen, G., Vilcinskas, A., Kogel, K. H., and Imani, J. 2012. The antimicrobial peptide thanatin reduc- es fungal infections in Arabidopsis. J. Phytopathol. 160:606610.

Kumar, S., Bhanjana, G., Sharma, A., Sidhu, M. C. and Dilbaghi, N. 2014. Synthesis, characterization and on field evaluation of pesticide loaded sodium alginate nanoparticles. Carbohydr. Polym. 101:1061-1067.

Lee, J. and Lee, D. G. 2009. Antifungal properties of the peptide derived from the signal peptide of the HIV-1 regulatory protein. Rev. FEBS Lett. 583:1544-1547.

Leslie, J. F. and Summerell, B. A. 2006. The Fusarium laboratory manual. Blackwell Professional, Ames, Iowa, USA. 388 pp.

Li, Q., Lawrence, C. B., Xing, H. Y., Babbitt, R. A., Bass, W. T., Maiti, I. B. and Everett, N. P. 2001. Enhanced disease resistance conferred by expression of an antimicrobial magainin analog in transgenic tobacco. Planta 212:635-639.

Long, S., Wendt, D. J., Bell, S. M., Taylor, T. W., Dewavrin, J. Y. and Vellard, M. C. 2012. A novel method for the large-scale production of PG-CNP37, a C-type natriuretic peptide analogue. J. Biotechnol. 164:196-201.

Makihira, S., Nikawa, H., Shuto, T., Nishimura, M., Mine, Y., Tsuji, K., Okamoto, K., Sakai, Y., Sakai, M., Imari, N., Iwata, S., Takeda, M. and Suehiro, F. 2011. Evaluation of trabecular bone formation in a canine model surrounding a dental implant fixture immobilized with an antimicrobial peptide derived from histatin. J. Mater. Sci. Mater. Med. 22:2765-2772.

Matsuzaki, K., Yoneyama, S. and Miyajima, K. 1997. Pore formation and translocation of melittin. Biophys. J. 73:831-838.

Nikawa, H., Fukushima, H., Makihira, S., Hamada, T. and Samaranayake, L. P. 2004. Fungicidal effect of three new synthetic cationic peptides against Candida albicans. Oral Dis. 10:221-248.

Olson, F., Hunt, C. A., Szoka, F. C., Vail, W. J. and Papahadjopoulos, D. 1979. Preparation of liposomes of defined size distribution by extrusion through polycarbonate membranes. BBA - Biomembranes 557:9-23.

Osusky, M., Zhou, G., Osuska, L., Hancock, R. E., Kay, W. W. and Misra, S. 2000. Transgenic plants expressing cationic peptide chimeras exhibit broad-spectrum resistance to phytopathogens. Nat. Biotechnol. 18:1162-1166.

Parente, R. A. and Lentz, B. R. 1986. Rate and extent of poly(ethylene glycol)-induced large vesicle fusion monitored by bilayer and internal contents mixing. Biochemistry 25:6678-6688.

Regente, M. C., Giudici, A. M., Villalaín, J. and De la Canal, L. 2005. The cytotoxic properties of a plant lipid transfer protein involve membrane permeabilization of target cells. Lett. Appl. Microbiol. 40:183-189.

Schmale, D. G. and Munkvold, G. P. 2014. Economic impact of mycotoxins. http://www.apsnet.org/edcenter/intropp/topics/ Mycotoxins/Pages/EconomicImpact.aspx (accessed December, 2014).

Vásquez, L. E., Guzmán, F., Patarroyo, M. E. and Arango, R. 2009. In vitro evaluation of antimicrobial peptides against Mycosphaerella fijiensis Morelet and their interaction with 
some chemical fungicides. Rev. Fac. Nal. Agr. Medellín 62:5063-5069.

Wang, X. J., Wang, X. M., Teng, D., Zhang, Y., Mao, R. Y. and Wang, J. H. 2014. Recombinant production of the antimicrobial peptide NZ17074 in Pichia pastoris using SUMO3 as a fusion partner. Lett. Appl. Microbiol. 59:71-78.

Wicklow, D. T. and Poling, S. M. 2009. Antimicrobial activity of pyrrocidines from Acremonium zeae against endophytes and pathogens of maize. Phytopathology 99:109-115.

Zasloff, M. 2002. Antimicrobial peptides of multicellular organisms. Nature 415:389-395.

Zeitler, B., Herrera Diaz, A., Dangel, A., Thellmann, M., Meyer, H., Sattler, M. and Lindermayr, C. 2013. De-novo design of antimicrobial peptides for plant protection. PLOS ONE 8:e71687. 